\title{
Thermal conductivity of porous ice in hailstone shells
}

\author{
Guoguang Zheng and Roland List \\ Department of Physics, University of Toronto, 60 St George Street, Toronto, Ontario M55 1A7, Canada
}

\begin{abstract}
The thermal conductivity and diffusivity of porous ice accreted on spherical and spheroidal hailstone models were measured over a density range of 620 $915 \mathrm{~kg} \mathrm{~m}^{3}$. By scanning the evolving surface temperature distributions during cooling in a cold airflow the thermal conductivity was varied in iterative fashion until the internal heat flux produced the correct surface temperature distribution. The results indicate a linear dependence of the thermal conductivity, $k_{\mathrm{i}}$, and diffusivity, $\alpha_{\mathrm{i}}$, on density. For example, lowering the density by $10 \%$ lowers $k_{\mathrm{i}}$ by $15 \%$. Within the range of cloud conditions, the density variations affect the thermal parameters more than temperature does. The results also indicate a continuous decrease of the thermal conductivity from bulk ice via consolidated porous ice to loosely packed snow.
\end{abstract}

\section{INTRODUCTION}

Large solid precipitation particles, such as graupel and hailstones, grow by accretion of supercooled cloud droplets on ice crystals or frozen droplets. If the droplets freeze immediately on contact they form a coating of rime in the form of an aggregate of more-or-less deformed frozen droplets, with the interstices filled with air. This leads to low-density rimed crystals or graupel. However, if the freezing is slow, denser ice structures such as transparent hailstone shells are created, leaving the accreted droplets indistinguishable from each other. Thus, it is no surprise that a wide variation of densities of ice particles has been reported. Natural graupel were found to range from 250 to $800 \mathrm{~kg} \mathrm{~m}^{-3}$ (List, 1958; Zikmunda and Vali, 1972; Heymsfield, 1978). The densities of natural hailstones collected at the ground and stored in freezers were measured at $820-920 \mathrm{~kg} \mathrm{~m}^{-3}$ (List, 1958; Macklin and others, 1960; List and others, 1970; Prodi, 1970; Matson and Huggins, 1980). The actual density of hailstones in clouds can be lower than that at the ground since melting often leads to the intake of meltwater by low-density ice regions (List, 1960; Macklin, 1963; Kidder and Carte, 1964; Prodi, 1970). The density can also be higher when spongy ice, a mixture of ice and water, is grown with the density approaching that of water. For artificial hailstones produced under dry growth conditions, Knight and Heymsfield (1983) measured densities of $310-600 \mathrm{~kg} \mathrm{~m}^{-3}$, values much lower than for bulk ice $\left(\rho_{\mathrm{i}}=915 \mathrm{~kg} \mathrm{~m}^{-3}\right)$. By not considering these variations, all previous cloud and precipitation studies have implicitly assumed that the thermal properties of porous (accreted) ice are equal to those of bulk ice.

Many studies of the thermal conductivity, $k_{\mathrm{i}}$, of bulk ice have been reviewed by Powell (1958). He shows that $k_{\mathrm{i}}$ varies with temperature and pressure, with a typical value of $k_{\mathrm{i}}=2.18 \mathrm{~W} \mathrm{~m}^{-1} \mathrm{~K}^{-1}$ at $0^{\circ} \mathrm{C}$. Thereby, $k_{\mathrm{i}}$ of ice is mostly dependent on temperature; it is little affected by ambient pressure. Measurements of the thermal conductivity of natural snow and low-density frost have also been reported in the literature (Kondrat'eva, 1954; Yen, 1962; Pitman and Zuckerman, 1967; Weller and Schwerdtfeger, 1971; Dietenberger, 1983; Östin and Andersson, 1991). It is significantly lower than that of bulk ice, and mostly depends on density, not on temperature (considering a range of $-40^{\circ}$ to $0^{\circ} \mathrm{C}$ ). Although theoretical modeling of the thermal conductivity of porous ice applicable to comet nuclei has been reported (Espinasse and others, 1991; Seiferlin and Kömle, 1991), little is known about the measured $k_{\mathrm{i}}$ values of porous ice with densities $>600 \mathrm{~kg} \mathrm{~m}^{-3}$ (Hobbs, 1974; Dietenberger, 1983; Östin and Andersson, 1991).

Porous ice consists of frost that is grown either over very long times by deposition of water vapor or over short times $(>1 \mathrm{~h})$ by accretion and freezing of supercooled water droplets. The theoretical modeling has demonstrated that the thermal conductivity of porous ice is heavily dependent on the ice texture (i.e. the degree of sintering among the single grains) (Espinasse and others, 1991; Seiferlin and Kömle, 1991). Therefore, the present investigation will be restricted to the determination of the $k_{\mathrm{i}}$ values of accreted porous ice applicable to hailstone shells over the density range of $600-910 \mathrm{~kg} \mathrm{~m}^{3}$.

\section{HEAT CONDUCTION}

In the analysis of heat transfer of a solid by conduction, both the thermal conductivity and diffusivity need to be known. The proportionality factor, $k_{\mathrm{i}}$, links the temperature gradient $(\partial T / \partial n)$ to the conductive heat flux $\left(\dot{q}_{\mathrm{con}}\right)$. Hence,

$$
k_{\mathrm{i}}=\frac{\dot{q}_{\mathrm{con}}}{\left(\frac{\partial T}{\partial n}\right)} .
$$


$k_{\mathrm{i}}$ is a material property which normally varies with temperature. Within the range of atmospheric temperatures for ice growth, the variation of $k_{\mathrm{i}}$ for bulk ice is within $\pm 10 \%$ (Powell, 1958).

The thermal diffusivity, $\alpha_{\mathrm{i}}$ is defined as the ratio of the thermal conductivity to the heat capacity per unit volume $\left(\rho_{\mathrm{i}} c_{\mathrm{p}}\right)$ :

$$
\alpha_{\mathrm{i}}=\frac{k_{\mathrm{i}}}{\rho_{\mathrm{i}} c_{\mathrm{p}}}
$$

where $\rho_{\mathrm{i}}$ and $c_{\mathrm{p}}$ are the density and the specific heat capacity of the solid, respectively. It represents the ability of the solid to conduct thermal energy relative to the ability to store it.

At the surface of an atmospheric ice particle, not exposed to accretion and freezing of collected cloud droplets, the heat transfer by conduction and convection into the surroundings $\left(\dot{q}_{\mathrm{s}, \mathrm{cc}}\right)$, the heat released by evaporation, sublimation or deposition $\left(\dot{q}_{\mathrm{s}, \text { esd }}\right)$ and by thermal radiation $\left(\dot{q}_{\mathrm{s}, \mathrm{r}}\right)$ must balance with the heat flux from the interior by conduction $\left(\dot{q}_{\mathrm{s}, \text { con }}\right)$ :

$$
\dot{q}_{\mathrm{s}, \mathrm{con}}=\dot{q}_{\mathrm{s}, \mathrm{cc}}+\dot{q}_{\mathrm{s}, \mathrm{esd}}+\dot{q}_{\mathrm{s}, \mathrm{r}} .
$$

Here it is assumed that the air flows around the test particles and that the interior heat transfer takes place only via heat conduction. The terms on the righthand side of Equation (3) are given by

$$
\begin{aligned}
\dot{q}_{\mathrm{s}, \mathrm{cc}} & =\frac{k_{\mathrm{a}} \overline{\mathrm{Nu}}}{D}\left(\bar{T}_{\mathrm{s}}-T_{\mathrm{a}}\right) \\
\dot{q}_{\mathrm{s}, \text { esd }} & =\frac{D_{\mathrm{v}} L_{\mathrm{s}} \overline{\mathrm{Sh}}}{D}\left(\overline{\rho_{\mathrm{vs}}}-\rho_{\mathrm{va}}\right) \\
\dot{q}_{\mathrm{s}, \mathrm{r}} & =\epsilon \sigma\left(\bar{T}_{\mathrm{s}}^{4}-T_{\mathrm{a}}^{4}\right)
\end{aligned}
$$

where $k_{\mathrm{a}}$ is the thermal conductivity of air $\left(k_{\mathrm{a}}=\right.$ $0.0224 \mathrm{~W} \mathrm{~m}^{-1} \mathrm{~K}^{-1}$ at $\left.-20^{\circ} \mathrm{C}\right), D$ is the particle diameter, $T$ is the temperature, $D_{\mathrm{v}}$ is the diffusivity of water vapor, $L_{\mathrm{s}}$ is the latent heat of sublimation, $\rho_{\mathrm{v}}$ is the water-vapor density, $\epsilon$ is the emissivity of the surface, $\sigma$ is the StefanBoltzmann constant $\left(\sigma=5.6697 \times 10^{-8} \mathrm{~W} \mathrm{~m}^{-2} \mathrm{~K}^{-4}\right)$, and $\mathrm{Nu}$ and $\mathrm{Sh}$ are the Nusselt and Sherwood numbers, respectively; the subscripts "s" and "a" represent surface and air, respectively; the overbar refers to the average over the entire particle surface. Within the temperature range and conditions of the present experiments, $\dot{q}_{\mathrm{s} \text {, esd }}$ and $\dot{q}_{\mathrm{s}, \mathrm{r}}$ are small $(\sim 5 \%$ and $<3 \%$, respectively) compared to $\dot{q}_{\mathrm{s}, \mathrm{cc}}$, and can be neglected in Equation (3). Thus, using Equation (1) for the surface, the heatbalance Equation (3) reduces to

$$
-k_{\mathrm{i}} \overline{\left(\frac{\partial T}{\partial n}\right)_{\mathrm{s}}} \cong \frac{k_{\mathrm{a}} \overline{\mathrm{Nu}}}{D}\left(\overline{T_{\mathrm{s}}}-T_{\mathrm{a}}\right)
$$

where $\overline{(\partial T / \partial n)_{\mathrm{s}}}$ is the average temperature gradient at the surface within the particle. The average Nusselt number, $\overline{\mathrm{Nu}}$, represents the non-dimensional, overall temperature gradient at the surface, and it provides a measure of the convective heat transfer occurring at the surface. For a given particle in a known fluid, $D, k_{\text {a }}$ and $T_{\mathrm{a}}$ are known. Since $\overline{\mathrm{Nu}}$ varies only with the physical properties of the fluid and the surface characteristics (i.e. roughness, size and geometry) and not with the internal properties (Incropera and DeWitt, 1990), the overall $\overline{\mathrm{Nu}}$ value of bulk-ice particles can also be used for the lowdensity particles with any $k_{\mathrm{i}} . \overline{\mathrm{Nu}}$ has been determined by Zheng and List (1996):

$$
\overline{\mathrm{Nu}}=(0.236+0.094 a) \operatorname{Re}^{(0.658-0.088 a)}
$$

where Re is the Reynolds number and $a$ is the aspect ratio of the particle. The average surface temperature, $\bar{T}_{\mathrm{s}}$, in Equation (7) is continuously and remotely measured and averaged with an AGEMA infrared surface-temperature scanning system, while $\overline{(\partial T / \partial n)}$ s can be determined by integrating over the area-weighted surface temperature gradients which are calculated by solving the heatconduction equation

$$
\frac{\partial T}{\partial t}=\alpha_{\mathrm{i}} \nabla^{2} T
$$

The calculation is performed with a given initial internal temperature field and the measured surface temperature field, and stepped forward in time to obtain the time variation of the internal temperature distribution (Zheng and List, 1996). Since the heat-conduction Equation (9) also requires knowledge of the thermal diffusivity $\alpha_{\mathrm{i}}$, which is related to $k_{\mathrm{i}}$ according to Equation (2), this quantity can be calculated with Equation (7) through iterations that converge towards the exact solution for $k_{\mathrm{i}}$. The main error sources in determining $k_{\mathrm{i}}$ are the uncertainties in $\overline{\mathrm{Nu}}$ and $\overline{(\partial T / \partial n)_{s}}$. The magnitude of the net uncertainty of $\left(\Delta k_{\mathrm{i}} / k_{\mathrm{i}}\right)$ is $<7 \%$.

\section{EXPERIMENT}

\section{The wind tunnel system}

The experiments were carried out in the University of Toronto Cloud Physics Wind Tunnel. It has a vertical closed circuit, and its temperature, velocity, pressure, liquid-water content and particle motions can be controlled (List and others, 1987). The measuring section of the tunnel is $70 \mathrm{~cm}$ high and has an inner cross-section of $17.8 \mathrm{~cm} \times 17.8 \mathrm{~cm}$ (Fig. 1). A double wall insulates the experimental region from the temperature gradient within the enclosing square "ring". The outer walls consist of four aluminum plates which are used to mount the particle-suspension system, the infrared AGEMA scanner and a door allowing access to the inner duct. The velocity in the measuring section can be varied between 0.5 and $30.0 \mathrm{~m} \mathrm{~s}^{-1}$, the air temperature between $20^{\circ}$ and $-35^{\circ} \mathrm{C}$.

\section{The test particles}

The spherical and spheroidal test models were created in a first set of experiments by accretion of supercooled liquid-water droplets on spherical ice embryos with initial diameters of $0.5 \mathrm{~cm}$. The embryos were prepared by freezing distilled water in rubber molds. A PVC stem with a diameter of $0.3 \mathrm{~cm}$ was then inserted and used to mount the particle on the suspension system. Such a gyrator was 


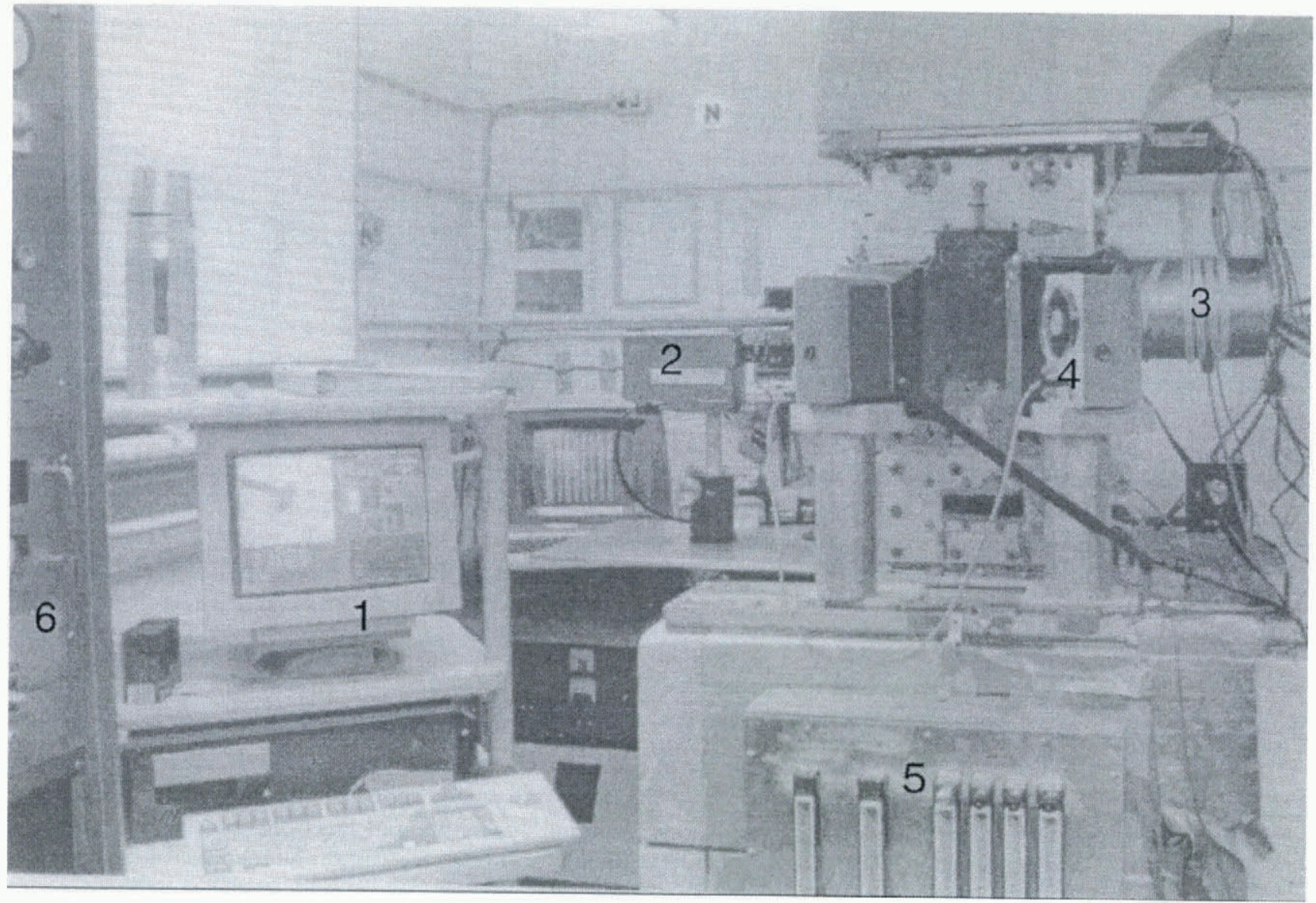

Fig. 1. Wind-tunnel measuring section, with AGEMA infrared thermal imaging system (1) and scanner (2); particlesuspension system (3), stroboscopes (4), water-injection control unit (5) and lemperature and air-velocity control panel (6).

designed to simulate the tumbling free-fall motion (Kry and List, 1974a,b). Ice particles with different densities were produced by changing the liquid-water content and the air temperature of the experiments. Then the particle surfaces were smoothed with fine sandpaper. This eliminates the effect of surface roughness on convective heat transfer and prevents the cold air from partially penetrating the porous ice particles when they are cooling in the airflow. The volume of each particle was determined using Archimedes' principle, with mercury as a fluid (Knight and Heymsfield, 1983). Then the density was calculated from its mass and volume. The resulting particles were smooth spheres and spheroids with major-axis diameters of $\sim 2.1 \mathrm{~cm}$, aspect ratios $(a)$ of $0.7-1.0$ and densities $\left(\rho_{\mathrm{i}}\right)$ of $620-915 \mathrm{~kg} \mathrm{~m}^{-3}$. A schematic test particle is shown in Figure 2. The $5 \mathrm{~mm}$ ice core represents $<2 \%$ of the total volume, and thus has only a minimal effect on the conductivity.

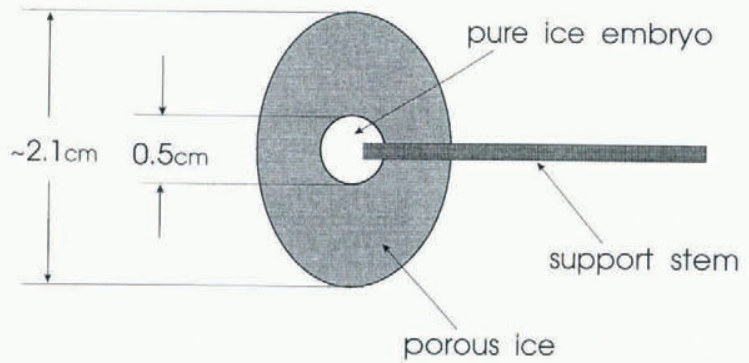

Fig. 2. Schematic diagram of the porous-ice accretion upon an ice embryo particle.

\section{Surface temperature measurements}

The second set of experiments involved an "AGEMA Infrared System Thermovision 800" thermal imaging system for remotely scanning the surface temperature of the porous test particles. The imaging detector has a spectral response over an $8-12 \mu \mathrm{m}$ wavelength window with a sensitivity of $\pm 0.13^{\circ} \mathrm{C}$ at $-15^{\circ} \mathrm{C}$. The spot size at the particle surface was $2.0 \pm 0.5 \mathrm{~mm}$; the scanning speed was 25 frames a second. About 400 points per $\mathrm{cm}^{2}$ of model surface could be resolved, i.e. enough to analyze the local heat transfer in detail. Calculation of the penetration depth of infrared radiation in bulk ice indicated that $98 \%$ of the incident radiation is absorbed within the first $40 \mu \mathrm{m}$ over the spectral range of interest (Hobbs, 1974). This means that the temperatures measured by the AGEMA system represent values very close to the model surface. Figure 1 gives an idea of the facility involved.

\section{Experimental set-up}

The experiments were started by exposing relatively warm particles $\left(\sim 6^{\circ} \mathrm{C}\right)$ to a cold airflow at $-15.0^{\circ} \pm 0.2^{\circ} \mathrm{C}$ with an air speed $\left(V_{\mathrm{a}}\right)$ of $921 \mathrm{~ms}^{-1}$, corresponding to Reynolds numbers $1.5 \times 10^{4} \leq \operatorname{Re} \leq 4 \times 10^{4}$. The initial particle temperature was determined by the cold room used for storing the particles prior to the experiment. The particles were forced to gyrate with a spin frequency of $9.5 \mathrm{~Hz}$ and a nutation/precession frequency of $-14 \mathrm{~Hz}$ about a horizontal axis, or to rotate at a rate of $10 \mathrm{~Hz}$ about the minor 
particle axis perpendicular to the (vertical) airflow. The minus sign of the frequency indicates that the sense of rotation is opposite to that of the spin (Kry and List, $1974 \mathrm{a}, \mathrm{b})$. All experiments were performed at laboratory pressure $(\sim 102 \mathrm{kPa})$.

\section{RESULTS AND DISCUSSION}

Figure 3 gives the time variation of the dimensionless average surface temperature, $\left(\bar{T}_{\mathrm{s}}-T_{\mathrm{a}}\right) /\left(T_{\mathrm{i}}-T_{\mathrm{a}}\right)$, of the porous ice-test particles, cooling in an airflow, as established with the AGEMA system. The lower the density of the particle, the faster the cooling, and the lower the surface temperature becomes. In other words, the density changes the thermal properties, affecting the temperature field at the surface and, therefore, within the particle.

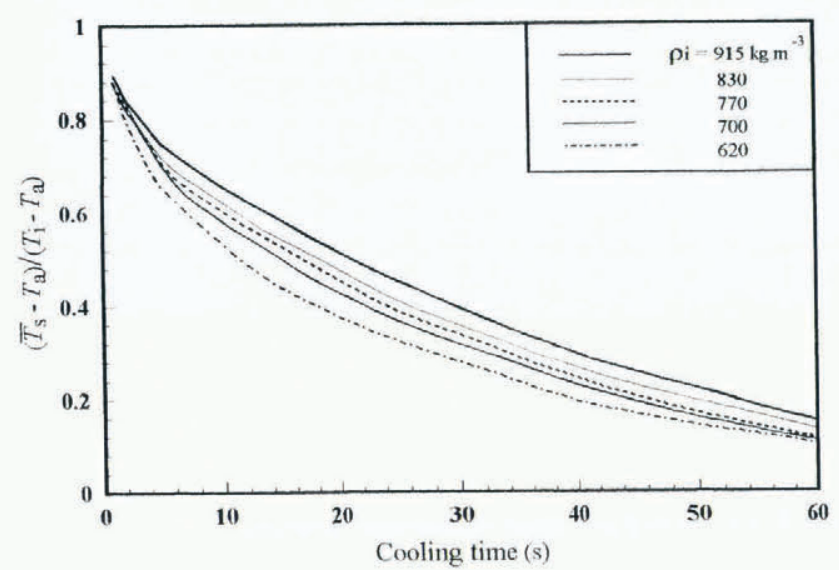

Fig. 3. The time variation of the dimensionless surface temperatures of ice particles $\left(D=2.1 \mathrm{~cm}, \alpha=0.7, T_{\mathrm{i}}=\right.$ $-6^{\circ} \mathrm{C}$ ) with different densities, cooling in an airflow $\left(T_{\mathrm{a}}=-15^{\circ} \mathrm{C}, V_{\mathrm{a}}=15 \mathrm{~ms}^{-1}, R e=2.6 \times 10^{4}\right)$.

The time variation of the average surface temperature was used to determine the thermal conductivity, $k_{\mathrm{i}}$ of the porous ice by Equation (7). Figure 4 is a plot of $k_{\mathrm{i}}$ of porous ice vs the particle density $\rho_{\mathrm{i}}$ at $T_{\mathrm{a}}=-15^{\circ} \mathrm{C}$. It is apparent that porous ice exhibits lower values of $k_{\mathrm{i}}$ than bulk ice. Porous ice with $\rho_{\mathrm{i}}=620 \mathrm{~kg} \mathrm{~m}^{-3}$ has only $55 \%$ of $k_{\mathrm{i}}$ for bulk ice. Dillard and Timmerhaus (1966) showed that $k_{\mathrm{i}}$ of bulk ice increased $5 \%$ and $11 \%$ as temperature decreased from $0^{\circ}$ to $-20^{\circ}$ and $-40^{\circ} \mathrm{C}$, respectively. Thus, under atmospheric cloud conditions, the density of porous ice influences the thermal properties more than temperature does. The variation of $k_{\mathrm{i}}$ with temperature may be neglected when the density varies.

Within the experimental range of this investigation (i.e., $620 \leq \rho_{\mathrm{i}} \leq 915 \mathrm{~kg} \mathrm{~m}^{-3}$ ), a linear least-square fit gives

$$
k_{\mathrm{i}}=3.176 \times 10^{-3} \rho_{\mathrm{i}}-0.726
$$

with a correlation coefficient of $0.996,\left[k_{\mathrm{i}}\right]=\mathrm{W} \mathrm{m}^{-1} \mathrm{~K}^{-1}$ and $\left[\dot{\rho}_{\mathrm{i}}\right]=\mathrm{kg} \mathrm{m}^{-3}$.

The dependence of $k_{\mathrm{i}}$ on density is caused by the ice structure with its various air inclusions. The presence of air bubbles enhances the cooling (Fig. 3) because there is

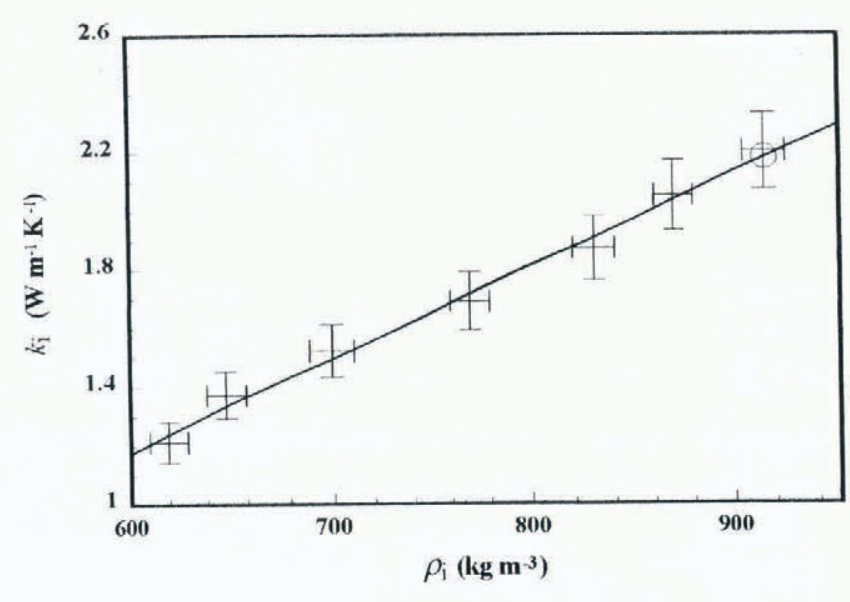

Fig. 4. The thermal conductivity, $k_{\mathrm{i}}$, of porous ice as a function of density, $\rho_{\mathrm{i}}$, at $T_{\mathrm{a}}=-15^{\circ} \mathrm{C}$. The correlation coefficient of the linear relationship between $k_{\mathrm{i}}$ and $\rho_{\mathrm{i}}$ is 0.996. The value of $k_{\mathrm{i}}$ for bulk ice is also plotted (open circle) for comparison.

less ice to cool. However, the values of $k_{\mathrm{i}}$ are lower (Fig. 4) because heat is not conducted well through the air enclosures. Physically speaking, $k_{\mathrm{i}}$ of porous ice is an effective thermal conductivity which is determined by the conductivities, volume fractions and shapes of the air spaces and the ice, and the degree of sintering. As expected by the theoretical modeling (Espinasse and others, 1991; Seiferlin and Kömle, 1991), the thermal conductivity of porous ice depends heavily on the ice texture. Therefore, the $k_{\mathrm{i}}$ values of the present investigation are valid for accreted porous ice applicable to hailstone shells.

The thermal diffusivity, $\alpha_{\mathrm{i}}$, of porous ice can be determined from the indirectly measured themal conductivity, $k_{\mathrm{i}}$, and the measured density, $\rho_{\mathrm{i}}$, of the test particle by Equation (2), and expressed as a function of $\rho_{\mathrm{i}}$ (see Fig. 5). $\alpha_{\mathrm{i}}$ becomes smaller as $\rho_{\mathrm{i}}$ decreases. However, the relative variation of $\alpha_{\mathrm{i}}$ with $\rho_{\mathrm{i}}$ is small compared to $k_{\mathrm{i}}$, since $\alpha_{\mathrm{i}}$ is reduced by only $18 \%$ as $\rho_{\mathrm{i}}$ decreases from 915 to $620 \mathrm{~kg} \mathrm{~m}^{3}$. This compares with $55 \%$ for $k_{\mathrm{i}}$. The ability of the porous ice to store heat is reduced with decreasing

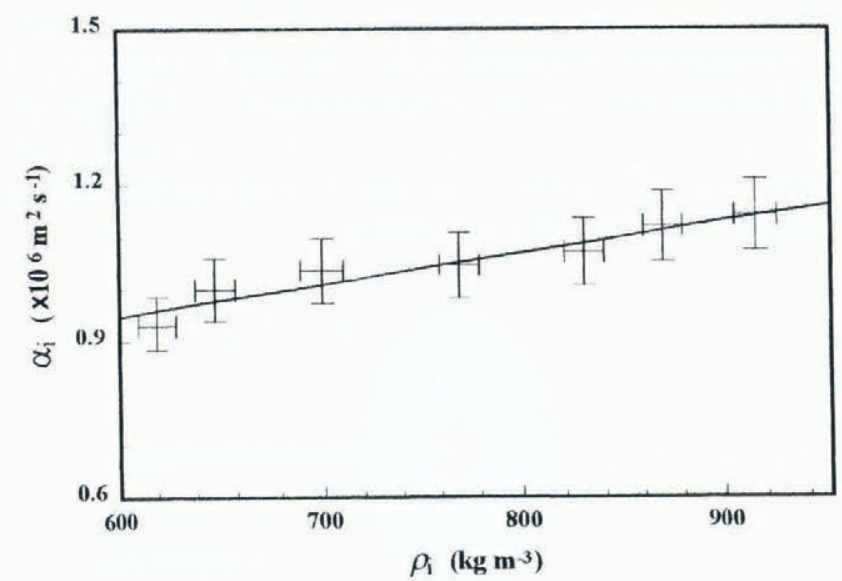

Fig. 5. The thermal diffusivity, $\alpha_{\mathrm{i}}$, of porous ice as a function of density, $\rho_{\mathrm{i}}$, at $T_{\mathrm{a}}=-15^{\circ} \mathrm{C}$. The correlation coefficient of the linear relationship between $\alpha_{\mathrm{i}}$ and $\rho_{\mathrm{i}}$ is 0.960 
$\rho_{\mathrm{i}}$. Thus, low-density ice with small $\alpha_{\mathrm{i}}$ responds faster to change in its environment than bulk ice. The value of $\alpha_{\mathrm{i}}$ can also be expressed by a linear relationship

$$
\alpha_{\mathrm{i}}=5.81 \times 10^{-10} \rho_{\mathrm{i}}+6.1 \times 10^{-7}
$$

over the range of density $620 \leq \rho_{\mathrm{i}} \leq 915 \mathrm{~kg} \mathrm{~m}^{-3}$, with a correlation coefficient of 0.960 , and $\left[\alpha_{\mathrm{i}}\right]=\mathrm{m}^{2} \mathrm{~s}^{-1}$.

Figure 6 summarizes the measurements of the thermal conductivity $k_{\mathrm{i}}$ of ice and snow as a function of density $\rho_{\mathrm{i}}$. Kondrat'eva (1954) determined $k_{\mathrm{i}}$ of snow (with stagnant air) for $\rho_{\mathrm{i}}<350 \mathrm{~kg} \mathrm{~m}^{-3}$, and correlated it to the square of the density $\left(\rho_{\mathrm{i}}{ }^{2}\right)$. Yen (1965) measured the effective thermal conductivity of unconsolidated and ventilated snow with a density of $376-472 \mathrm{~kg} \mathrm{~m}^{-3}$. He also found a dependence of $k_{\mathrm{i}}$ on $\rho_{\mathrm{i}}{ }^{2}$. Pitman and Zuckerman (1967) and Weller (1971) determined the thermal conductivity of snow with densities of $100-620$ and $420-570 \mathrm{~kg} \mathrm{~m}^{-3}$, respectively, at temperatures varying from $-5^{\circ}$ to $-88^{\circ} \mathrm{C}$ and $-17^{\circ}$ to $-60^{\circ} \mathrm{C}$. These authors found that the dependence of $k_{\mathrm{i}}$ on temperature became smaller as the temperature increased. Again, $k_{\mathrm{i}}$ of snow was more sensitive to changes of density than to temperature (as found for porous ice). Pitman established that the effective thermal conductivity of snow is proportional to $\rho_{\mathrm{i}}$ for $400<\rho_{\mathrm{i}}<620 \mathrm{~kg} \mathrm{~m}^{-3}$ and to $\rho_{\mathrm{i}}{ }^{2}$ for $\rho_{\mathrm{i}}<400 \mathrm{~kg} \mathrm{~m}^{-3}$. Östin and Andersson (1991) determined the effective thermal conductivity of frost grown in a forced air stream over a density range of $80<\rho_{\mathrm{i}}<680 \mathrm{~kg} \mathrm{~m}^{-3}$. Their experimental data were described by the polynomial

$k_{\mathrm{i}}=\left(-8.71 \times 10^{-3}\right)+\left(4.39 \times 10^{-4}\right) \rho_{\mathrm{i}}+\left(1.05 \times 10^{-6}\right) \rho_{\mathrm{i}}{ }^{2}$.

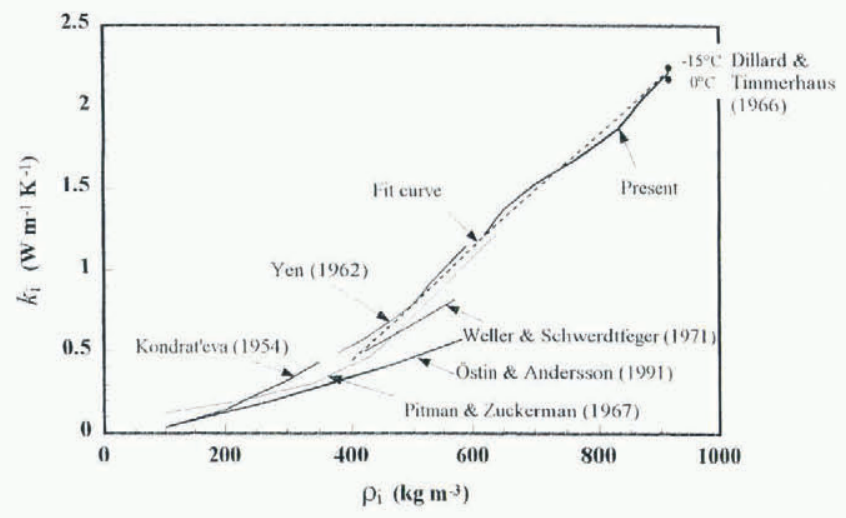

Fig. 6. The thermal conductivity, $k_{\mathrm{i}}$, of bulk ice, snow, frost and porous ice as function of density, $\rho_{\mathrm{i}}$. All measurements were made at $T_{\mathrm{a}}=0^{\circ}$ to $-17^{\circ} \mathrm{C}$. The dash line represents the best linear fit of the data within the range of $400 \leq \rho_{\mathrm{i}} \leq 915 \mathrm{~kg} \mathrm{~m}^{-3}$, with a correlation coefficient of 0.992. This fit does not include the frost measurements of Östin and Andersson.

Their $k_{\mathrm{i}}$ values were within a factor of 1.31 lower than those of other investigations in the density range $100<\rho_{\text {i }}$ $<550 \mathrm{~kg} \mathrm{~m}^{-3}$ (Fig. 6). This is not surprising, because frost is grown by deposition of water vapor, whereas snow is produced by the combined processes of water-vapor deposition, aggregation of ice and/or other snow crystals and accretion of supercooled water droplets. Thus, frost and snow have different ice structures (texture) which, at the same density, have different thermal conductivities. As shown in Figure 6, the $k_{\mathrm{i}}$ values of porous ice are between those of bulk ice and snow or frost. The linear relationship between $k_{\mathrm{i}}$ and $\rho_{\mathrm{i}}$ for porous ice blends smoothly with that of snow with $\rho_{\mathrm{i}}>400 \mathrm{~kg} \mathrm{~m}^{-3}$. The linear fit to the $\left[k_{\mathrm{i}}, \rho_{\mathrm{i}}\right]$ curves for $400 \leq \rho_{\mathrm{i}} \leq 915 \mathrm{~kg} \mathrm{~m}^{3}$ is

$$
k_{\mathrm{i}}=3.356 \times 10^{-3} \rho_{\mathrm{i}}-0.891
$$

with a correlation coefficient of 0.992 . This expression is close to that given by Equation (10).

\section{SUMMARY AND CONGLUSIONS}

Two sets of experiments were carried out in a Cloud Physics Wind Tunnel. First, porous ice particles with different densities were grown by accretion of supercooled water droplets. Then the thermal conductivity and diffusivity of the accreted porous ice were measured by remotely scanning the surface temperature of cooling particles and modeling the internal heat fluxes. The conclusions are:

(1) Under similar external cooling conditions, the surface temperature cools faster for porous ice with a low density than for bulk ice. The lower the density is, the faster the porous ice responds to the temperature of the environment because of its reduced heat capacity.

(2) Both the thermal conductivity, $k_{\mathrm{i}}$, and diffusivity, $\alpha_{\mathrm{i}}$, of accreted porous ice depend on density, $\rho_{\mathrm{i}}$, and can be described by linear relationships over the density range $400 \leq \rho_{\mathrm{i}} \leq 915 \mathrm{~kg} \mathrm{~m}^{-3}$. Lowering $\rho_{\mathrm{i}}$ by $10 \%$ lowers $k_{\mathrm{i}}$ by $15 \%$ and $\alpha_{\mathrm{i}}$ by $5 \%$. Thus, the effect of $\rho_{\mathrm{i}}$ on $k_{\mathrm{i}}$ is more significant than on $\alpha_{\mathrm{i}}$.

(3) Within the range of cloud conditions, the density of accreted porous ice influences the thermal properties more than temperature. Therefore, the density variation needs to be considered.

(4) The results bridge the gap of the thermal properties of snow or low-density ice and bulk ice.

These results can be used to model the growth and heat transfer of natural and artificial hailstones and to understand better their growth and melting. They can also help in the interpretation of the growth structure of hailstones. The conclusions are restricted to artificially grown, dry hailstone shells with air enclosures. The heat conduction at a given density will vary only slightly with the ice framework, which in turn is mostly affected by the size of the accreted cloud droplets. The measurements are not directly applicable to ice densities of cometary nuclei, where ice-structure variations may be much larger and, in addition to crystalline ice, amorphous ice may be encountered. Further, the mass transfer through the gaseous phase may play a much larger role in the effective thermal conductivity because of internal convection, the long time-scales and the extremely small air pressures involved. Further investigations may consider the thermal 
conductivity of porous ice in the form of compacted frost, and the dependence of the thermal conductivity on ice texture and air pressure.

\section{ACKNOWLEDGEMENTS}

This work was sponsored by the Natural Sciences and Engineering Research Council of Canada (NSERC). One of the authors (G.Z.) is grateful for financial support by the University of Toronto and the Chinese Government. This work would not have been possible without the AGEMA Infrared Thermal Imaging System which was gracefully made available by the Ontario Lightwave and Research Centre (OLLRC) at the University of Toronto.

\section{REFERENCES}

Dietenberger, M. 1983. Generalized correlation of the water frost thermal conductivity. Int. J. Heat Mass Transfer, 26, 607-619.

Dillard, D.S. and K. D. Timmerhaus. 1966. Low temperature thermal conductivity of solidified $\mathrm{H}_{2} \mathrm{O}$ and $\mathrm{D}_{2} \mathrm{O}$. Pure Appl. Cryog., 4, 35-44.

Espinasse, S., J. Klinger, C. Ritz and B. Schmitt. 1991. Modeling of the thermal behavior and of the chemical differentiation of cometary nuclei. Icarus, 92, 350-365.

Heymsfield, A.J. 1978. The characteristics of graupel particles in northeastern Colorado cumulus congestus clouds. J. Atmos. Sci., 35 $284-295$.

Hobbs, P. V. 1974. Ice physics. Oxford, Clarendon Press.

Incropera, F.P. and D. P. DeWitt. 1990. Fundamentals of heat and mass transfer. Third edition. New York, etc., John Wiley and Sons.

Kidder, R. E. and A. E. Carte. 1964. Structures of artificial hailstones. J. Rech. Atmos., 1, 169-181.

Knight, N.C. and A.J. Heymsfield. 1983. Measurement and interpretation of hailstone density and terminal velocity. 7. Atmos. Sci., $406), 1510-1516$

Kondrat'eva, A.S. 1954. Thermal conductivity of the snow cover and physical processes caused by the temperature gradient. SIPRE Transl. 22.

Kry, P. R. and R. List. 1974a. Aerodynamic torques on rotating oblate spheroids. Phys. Fluids, 17 (6), 1087-1092.

Kry, P. R. and R. List. 1974b. Angular motions of freely falling spheroidal hailstone models. Phys. Fluids, 17 6), 1093-1102.

List, R. 1958. Kennzeichen atmosphärischer Eispartikeln. 2. Teil: Hagelkörner. Z. Angew. Math. Phys., Ser. A, 9 3), 217-234.

List, R. 1960. Growth and structure of graupel and hailstones. In Weickmann, H., ed. Physics of precipitation. Washington, DC, American Geophysical Union, 317-324. (Geophysical Monograph 5.)

List, R., J. -G. Cantin and M. G. Ferland. 1970. Structural properties of two hailstone samples. J. Atmos. Sci., 27 (7), 1080-1090,

List, R., G. B. Lesins, F. Garcia-Garcia and D. B. McDonald. 1987. Pressurized icing tunnel for graupel, hail and secondary raindrop production. 7. Atmos. Oceanic Technol., 4(3), 454463.

Macklin, W. C. 1963. Heat transfer from hailstones. Q. J. R. Meteorol. Soc., 89 (381), 360-369.

Macklin, W. C., E. Strauch and F.H. Ludlam. 1960. The density of hailstones collected from a summer storm. Nubila, 3 1), 12-17.

Matson, R.J. and A. W. Huggins. 1980. The direct measurement of the sizes, shapes and kinematics of falling hailstones. J. Atmos. Sci., 37 (5), 1107-1125.

Östin, R. and S. Andersson. 1991. Frost growth parameters in a forced air stream. Int. 7. Heat Mass Transfer, 34, 1009-1017.

Pitman, D. and B. Zuckerman. 1967. Effect of thermal conductivity of snow at $-88^{\circ},-27^{\circ}$ and $-5^{\circ}$ C. J. Appl. Phys., 38 6), $2698-2699$.

Powell, R.W. 1958. The thermal conductivities and expansion coefficients of water and ice. Adv. Phys., 7 26), 276-297.

Prodi, F. 1970. Measurements of local density in artificial and natural hailstones. 7. Appl. Meteorol., 9, 903-910.

Seiferlin, G. and N. I. Kömle. 1991. A model of the thermal conductivity of porous water ice at low gas pressures. Planet. Space Sci., 39 (3), 507513.

Weller, G. E. and P. Schwerdtfeger. 1971. New data on the thermal conductivity of natural snow. J. Glaciol., 10 (59), 309-311.

Yen, Y.-C. 1962. Effective thermal conductivity of ventilated snow. 7 Geophys. Res., 67 (3), 1091-1098.

Yen, Y.-C. 1965. Effective thermal conductivity and water vapor diffusivity of naturally compacted snow. J. Geophys. Res., 70 8), 1821-1825.

Zheng, G. and R. List. 1996. Convective heat transfer of rotating spheres and spheroids with non-uniform surface temperatures. Int. J. Heat Mass Transfer., 39, 1815-1826.

Zikmunda, J. and G. Vali. 1972. Fall patterns and velocities of rimed ice crystals. 7. Atmos. Sci., 29(7), 1334-1347. 